\title{
The Relationship between Knowledge Organizational Dimensions and Informational Technology Tools in Knowledge Operation Management (Suggested Model)
}

\author{
Dr. Ali Hadi Jebrin \\ Faculty of Business, Dept: of Business Administration, Middle East University \\ P.O. Box 383, Amman 11831, Jordan \\ E-mail: daad_ali@yahoo.com
}

Received: February 9, $2011 \quad$ Accepted: March 29, $2011 \quad$ doi:10.5539/ijbm.v6n9p234

\begin{abstract}
Highlight the importance of the present study in developing a methodology for consideration in view of the expected contribution to clarifying the theoretical profile "for the operation management" in addition to its contribution to the transfer of the monuments of supporting regulatory dimensions and the technological information tools to the experimental field. Here is a modest contribution where there is a dire need for further research.

Therefore, the research goals can be specified as attempt to explore scientific assets for theoretical concerns of the subject knowledge, tools, and strategies. (The contents of this effort aimed at establishing a new understanding of the meaning of knowledge management contents of organizational knowledge dimensions and its operational tools).

The study is interested in investigating the relationship between technological information tools and organizational dimensions and knowledge operations management standards. This helps to face fundamental issues in knowledge and its management.
\end{abstract}

Keywords: Knowledge operation management, Information technology, Knowledge strategies, Organizational knowledge, Knowledge dimensions

\section{Introduction}

Successful knowledge operation management requires development of a clear formulation of operational regulatory dimensions, in addition to an understanding of information technology tools and their relationship. The subject was applauded by researchers, although it is still applied in its first stage in operational management studies. Identifying the relationship dimensions and tools have an impact on many business organizations in building strategies and in the relationship value and impact force between these dimensions and tools. Reviewing what was written on the subject, it was realized that it is still in the process of the theoretical concerns that are input to establish an input to pilot studies dealing with forms in the discussion of the theme of the relationship.

Despite the recognition of studies on the importance of distinguishing between knowledge of operation management dimensions and technological information tools by interested writers there is no clear idea about how to continue a relationship for both axes on knowledge management in organizations. Moreover, the time itself cannot assess implicit aspects of the question of the relationship between them and the impact on knowledge operations management.

In this sense we came from a strategic perspective which focuses on the relationship between organizational dimensions and informational tools in an attempt to explain and evaluate the value of that relationship in achieving effective knowledge management in general and knowledge of operation management tools in particular.

Based on the foregoing, one can highlight the importance of the present study in developing a methodology for consideration in view of the expected contribution to clarifying the theoretical profile "for the operation management" in addition to its contribution to the transfer of the monuments of supporting regulatory dimensions and the technological information tools to the experimental field. Arabic studies in this area remain very rare, and here is a modest contribution where there is a dire need for further research.

\section{The importance of the present research and its objectives}

In industrial countries, knowledge management theme clearly reflected the importance not only with the competencies from the studies and research, but also in spread to the reality of the organizations practice. It is 
believed that developing countries continued to face problems associated with malfunctioning originated from the knowledge, tools and its implications for organizations to invest in those states. Based on the foregoing, our evolving research comes to study the impact of the relationship between organizational knowledge operational dimensions and technological knowledge tools in knowledge management.

Therefore, the research goals can be specified as:

1) Detect trends in knowledge organizational dimensions and knowledge technology tools and possible support of outsourcing operational knowledge management process under organizational strategy and objectives of its operations.

2) Attempt to explore scientific assets for theoretical concerns of the subject knowledge, tools, and strategies. The contents of this effort aimed at establishing a new understanding of the meaning of knowledge management contents of organizational knowledge dimensions and its operational tools.

3) Clarify the theoretical profile of operational knowledge management topic, in addition to its contribution to transfer those landmarks which maintain operational regulatory dimensions and their relationship to knowledge management and its standards in the light of the overall strategy of the organization and its operations.

\section{Research Problem}

Despite the significant evolution in operations management, "knowledge" as a concept still prevails in a limited way, which is one of the technical problems. However, notable in the field of operations management, especially when it began to focus on operations and its decisions as strategic decisions, contributing to the "knowledge" location according to this perspective. Since knowledge is one of the basic principles of operational activities, it gained the same features that are of operations in the theoretical treatment. Those studies attempted to address the issue of assessing the relationship between organizational knowledge dimensions and informational technological tools in knowledge management.

Studies revealed that focus on information and communication technology tools cannot bring benefits unless it is appropriate for organizational dimensions of knowledge. But how to achieve relationships, proportionality and evaluation between the two parties, remains an unanswered question in conceptual and empirical domains. Thus, the present study attempts to address this problem. The study is interested in investigating the relationship between technological information tools and organizational dimensions and knowledge operations management standards. This helps to face fundamental issues in knowledge and its management. This study is a serious attempt to provide answers to the following questions about the contents task of this problem:

- Is developing a strategic scenario in relation with knowledge and organizations general strategy and business strategy? and why?

- Do high level managements have scenarios about organizational knowledge dimensions contrary to popular belief that knowledge management knows the information and communications technology? If so, what?

- How can the relationship between organizational and technological dimensions towards achievements of effective operational management knowledge be assessed and evaluated?

- How, and when, do organizational knowledge dimensions interact with measures of knowledge management or help or roles and constitute a work relationship?

\section{Research methodology and approach}

Studying organizational knowledge dimensions trends and technological information knowledge requests building a model that reflects the possibility of clarifying the relationship value between organizations. A model framework and component that crystallize ideas to build knowledge management worth based not only on what tools and technology communications give ,but field of tutorial and concepts of perception that includes other items and related knowledge organizational dimensions may participate in the elaboration of the thought to achieve strategic goals through acquisition and move the operational knowledge .

The model was drafted based on the following directions:

1) The belief that rationale has a great importance in the interpretation and analysis of results, but the growing use of knowledge changes this to rational operational strategy to be recognized through knowledge management model in more comprehensive and effective interpretation based on knowledge management concept that is determined by knowledge tools and communications technology.

2) Reviewing the specialized literature and philosophy, the researcher did not find any model for measuring the operational knowledge management, so the researcher developed and specified dimensions in light of what was mentioned in the introduction and the problem of research. Dimensions such as the totalitarian operational, strategic, informative were contributed to its drafting (Zack, 1999: 124). As well as on the formulation and design of the model as reflected in seeking the fact that the observed development in the operational management field and strategic decisions is getting this location according to this perspective.

Consequently we find it appropriate to discuss the subject as follows: 
Introduction:

Problem of research:

The importance of research and its objectives:

Research methodology and approach:

First: knowledge management portal:

Secondly: the first dimension, the relationship between knowledge and organizational strategy and operations (why).

Third: second and third dimension, operational, organizational knowledge (what is it).

Fourth: the fourth dimension, knowledge devices and communications technology (what is it).

Fifth: measuring operational knowledge management (how).

Sixth: conclusions and recommendations.

\section{Reference}

\section{First: Introduction to knowledge management}

Characterized literature during the twentieth century, especially after the 1980's throughout of that century to give the subject knowledge efforts as well Western culture since the era of the Greeks. The prevailing influence of knowledge created a number of studies and research, theories, entrances, views, gadgets. Increasingly the focus turning towards understanding the formation of knowledge as an iterative process with practical guidance between people with different backgrounds and their own interpretation on their respective areas of work (Katzenback, 1993, P. 108). Kirkeby (1993) suggested that the two approaches to study knowledge management theory are:

First the engineering portal, which focuses on non-functional dimensions to solve problems and to understand the interactions between systems without moving toward one part, which equals the systematic approach. These early stages of the project are set of items with combined structure representing the whole, where the formation of these items or portions from a threaded chain better overall situation of the project.

Second entrance, called administrative/portal, regulatory philosophy revolves around a list of four major entries as follows: (Hendriks, 2001, P.58):

1) Knowledge storage portal: this portal focuses on knowledge set of properties with technological know-how and technology operations that are different from human knowledge.

2) Knowledge operations approach: the idea that projects are temporary systems and amendment resolution contains study regulator based on humanitarian concepts in knowledge, knowledge exist if anyone knows (acquisition, creation, and distribution).

3) Organizational education portal: this portal is based on researches seeking knowledge plays a central role in the initiative for trends of cooperation and collaboration with institutions in providing knowledge assets.

4) The knowledge asset portal: the idea of this portal includes the operational rationality model that organizations or projects are not tools (plan, control, and assessment) but expectations, work and learning systems which defy rational approach that strengthens outs to capital and labor, aware of the benefit of knowledge. According to (Boisot), this portal focuses on formulating points out of the growing importance of knowledge of both touchable knowledge and untouchable knowledge of others and try to distinguish between them (Information Space) (Jibreen, 2003, P. 4).

Scientific efforts gathered to study knowledge management (how), emerged ideas addressed this subject, (Boisot) conceived through, the concept of knowledge management in its administrative approach is similar concept suited to previous approach (knowledge storage, operational, organizational learning, rationalist) studied in-depth and broad, philosophy and concept without minimizing practically the importance of the engineering approach (Boisot, 1995, P. 30). Taking into account the responsibilities of the senior management must be events, activities and strategic objectives of the organization and its resolutions, and this explains in its contents "knowledge management" importance in operational decision-making. Foregoing that knowledge tasks are defined in agreement of most writers and researchers as an administrative and strategic problem within senior management priorities and precedence in the operational goals. This approach is consistent with the direction we discussed that includes the two sides of knowledge management: First: organizational cognitive dimensions, second contents under the concept of technological information tools and to discover and evaluate their relationship under understanding comprehensive and fundamental operational organization strategy. Credibility of the study model will be proved theoretically.

\section{Secondly: the first dimension: the relationship between knowledge and organizations strategy and operations "why"}

During the last two decades organizations began to realize that the best information that is processed quickly can provide competitive benefits to the organization. With the growing importance of "knowledge" is getting attention of global organizations managers towards change in their management style, if they want competitive advantage. 
As most managers perceive knowledge management as strategic operational objectives orientation towards creativity and ideas. This requires acquisition of knowledge from its foreign and internal environment and analysis.

Strategic planning process taking into account trends analysis, organization mission, philosophy and policies and methods of achieving goals requires senior management and other managers to strengthen their knowledge and provide information organization, as well as the need for experienced personal and professional manner to see the future and avoid future obstacles. Further, study values and organizational behavioral trends and persons, grand, and the surrounding community to address the current threats and changes in the environment to enable the organization to create the desired effective change that urges the organization towards creativity and pioneering work that creates ideas and new projects.

Organizational need to strategic perception passes, after upper and middle management perception about the environmental challenges and calls on organizations to acquire knowledge and to avoid the risk of strategic clone perceptions (Al-Khafaji, 2004, P.68), supported the unilateral vision of technological information and communications techniques, unless supported by personal and collective knowledge and value-and faith-based and organizational factors and their impact and associated in the life of the organization and the effectiveness of their area and more influential, creative and renewal or change and transform administratively, systematically and strategically.

Guided by what was mentioned, organizational strategy and operations strategic must be developed together because the strategic option can be managed by organizational knowledge and technological knowledge tools, in the same direction operations strategy must define management operations functionality objectives which will help them to excel in the competition fever. This is consistent with the contemporary trends in an efficient management focused on operational knowledge with interest in business organizations to achieve their goals.

Confirmation of the above, this study methodology for operational knowledge management content deals with two-way- field of the dimension - a title-confirm studies (Packendroff, 1995, P. 309): First axes, covering under the concept of organizational knowledge and dimensions could be clarified as follows:

1) Signal by (Vijay) confirms the organizational dimensions as a basis from which to build qualified management of knowledge are designed to improve the effectiveness of knowledge operations management (Vijay, 2005, P. 19).

2) Understand organizational operations as Thomas concluded that the fact and vital part of knowledge management basics (Thomas, 1999, P. 69).

3) Tracker to books on contemporary trends regarding knowledge management showed writers and researchers notes insistence on attention to specify dimensions of organizational knowledge (Hendriks, 2001, P. 57).

4) A study by (Lee) found that managers focus on addressing the relevant problems and a link to the dimensions and regulatory climate implications and the involvement of this focuses on team building, creativity, knowledge, and value analysis (Lee, 1993, P. 16).

The second axis under the concept of ideas of informational technology and its multiple tools (methods, formulas, models, software, and electronic analysis) can be checked by the following:

1) It has become a threat to business organizations to ignore the impact of communications and knowledge technology and understanding of building knowledge management "requirements" that absorb knowledge operations.

2) A study by (Mills) concludes that updated information systems improve access to the required information to achieve policy change that can see changes in the environment to change the organizational situation itself in general (Mills, 2007, P. 234).

3) Intensive use of electronic computers led to advance idea of integrated production systems concept that occurs through linking organizations departments with other terminals to create integrating systems. These smart techniques aimed at developing operations systems to achieve the organization's global competitive advantage.

After the discussion of the two axes and their source, in response to complete our model, compromising concept which pay it - a title for the study-shed light on the contents of the relationship between the two axes:

1) Organizations ability to compete determined in the light of their ability to achieve the "relationship" between the knowledge organizational dimensions and knowledge instrumental dimensions, communications technology and the surrounding environmental conditions.

2) Some of organizations failure is due to adopting the concept of knowledge management exclusively with tools and communications technology even though they have been applauded by the people at large in the world.

3) The objective of the development of this framework is to work until you find the problem and methodology: (why, how, when) it is possible that organizational dimensions and technological tools have a valuable and 
useful relationship for operational knowledge management.

Thus (Camillus) study concluded with important step in this direction by providing "relationship" schools (Camillus, 2008, P. 520):

1) Strategy Implementation School.

2) Integrated Structured School (Gestalt School).

First school in its concepts introduced the relationship between the strategic planning processes and organizational key elements within the organization, while the second school emphasizes integrated structure for natural or biological phenomena that created organizational dimension with characteristics which cannot be derived from parts, because organizations must focus on all items properties and not information and communication technologies in the field only and to enhance their capacity to provide knowledge that achieves competitive advantage. (Teece) presents a perspective which indicates that organization problems linked by the product/service/ or operations is a process that needs to adapt and internal organizational consensus between activities and technical tests (Teece, 2000, P. 289). Thus, this study comes together on the critical line that began preparing to measure operational knowledge performance under knowledge operations management concepts. Perhaps in that we have put forward in parallel contemporary research in our area of interest.

It should be noted that researcher's theoretical discussion interest concept of relationship aimed at elaborating a new portal for how to know operational knowledge management standards for organizations through the relationship between organizational knowledge dimensions and knowledge tools for technological knowledge and communications under strategic awareness. This portal is based on the idea of essential operational standards knowledge management are determined in the study of internal and external aspects of the environment of the organization in light of the overall strategies to express variables or special elements of operational knowledge management with responding to a relationship. According to (Cleuck), these activities are: production, human resources, finance, structure and research and development. While as (King), (Henry) stated resources and organizational abilities are selected in the following manner: profits, administrative structure, resources, technical regulations, organization (King, 1997, P. 475) (Stacey, 1997, P.32). In this context both (Wheelen and Hunger) suggested three key variables in the analysis and diagnosis positions and strategies. They are the structure and organization, technology and resources.

On this basis, the researcher found in all of the contribution to the unification efforts under include cognitive representation activities regarding our operational knowledge management research found that structure, organization and human resources management would be the operational standards in knowledge management with objective and subjective determinants.

\section{Third: second and third dimensions: operational organizational knowledge (what)}

Knowledge featured atmosphere in organization which represents the philosophy, culture and environment in the organization, basic rules that explain to people how to behave. In this regard (Hendriks) emphasized that managers must understand that tools, technical instruments, communication technology and information tools are insufficient, as did not reflect the values and beliefs by workers and people of the importance of good especially preference the tacit knowledge when workers serve real key to knowledge (mind and intelligence) (Hendriks, 2001, P. 62). Also, the degree of development and improving knowledge and its distinctive results are achieved when senior management trusts in the efficiency of all individuals in their contributions and knowledge pioneer activities at work. According to (Rosabeth), change individuals will lead to change value of knowledge defined in the guideline so that organizations will be affected.

In light of this, organization must keep in mind that organizational knowledge is a primary force in their strategies as stated by (Rosabeth) that individuals having ideas and concepts and values and innovations to determine everything possible achieved to high levels of knowledge, it requires generating high levels of collective cooperation and coherence because this will create organizational commitment and desire to pursue knowledge and procedures provided (Rosabeth, 1991, P. 43).

Based on the foregoing, the researcher found that there are some basic variables which represent the core of the concept of organizational attributes/characteristics to be consistent with what is presented within model's philosophy dimensions as below:

Knowledge: work methodology.

Knowledge: the responsibility of senior management as it is for individuals and groups.

Knowledge: the responsibility of all departments and employees.

Knowledge: competitive advantage and strategic thinking.

Knowledge: is important as operations are at the development and improvement level.

Knowledge: should be discussed more to see and solve problems.

So the administration's success depends on the ability to influence organizational behavior and positive balance in the role of contributions required from each individual within the organization. For organizational practices to 
become a successful tool in supporting strategies and management processes to improve their capacity, (Don) stresses on individual contribution in support of working knowledge required by what is gained of skill and experience through acquisition and retention and provide knowledge which enables it to achieve contributions that lead to the development of operational knowledge management standards (Don, 2005, P. 38). Perhaps (Ishikawa) highlighted the concept of collaboration of individuals, including their rights to deliver knowledge and provide information and advice and suggestions. Cooperation activity promotes group cohesion and teamwork content oriented goals and operational plans (Ishikawa, 1988, P. 133).

To achieve this, the researcher finds the need to identify the organizational aspects of collective knowledge as follows:

1) Grant opportunities to interact through teams by community members and the spirit of cooperation enabling organizational knowledge of vocabulary working group basis knowledge work.

2) Direct the interaction between individuals and groups and between the individual and the community and each section with other departments to analyze the contents of their work in the light of experience to assess problems and find solutions.

3) Connect compatibility process between operational knowledge at senior management levels and knowledge of other departments levels toward creating harmony and common understanding towards efficient operational knowledge management.

4) Individual and collective contributions lead to (what data and information stored) value their knowledge which represents the concept of organizational entity memory in organizational knowledge world away to operational knowledge management.

The importance of searching for individual and group knowledge has reflected the interest of many writers in the attempt to meet the needs of individuals and demonstrate by their knowledge and their functions in more challenging ways. The researcher in turn stresses the importance of the operational aspects of organizational knowledge that the individual and group in this dimension means its individual mental, emotional and socialized interaction with the senior management team. In this regard, some aspects of organizational knowledge could clarify achieving their strategic organization and as an important dimension in a close relationship with tools and technological communication. Knowledge management should pay distinctive attention to it because it represents a basic axes task and competing process and as featured below:

- Knowledge: provide individuals with contemporary trends and gateways through training and organizational learning.

- $\quad$ Knowledge: the application of the "feedback" between senior management and personnel development plans and policies in relation to environmental variables.

- Knowledge: Awareness and promoting knowledge about quality for teams and distinctive individuals.

- Knowledge: producing organization with available plans that can turn into new business (a new product, development, design, and processes).

\section{Fourth dimension: information and communication technology tools (what is it)}

Organizations are currently are creative in operational management tools and techniques with high level that these organizations have the capacity to handle new information and convert it quickly to achieve its operational and strategic objectives. Thus these organizations run the risk of informational death in the information society. Organizational technical and technological communication with its equipment used in it its product or services selected affects almost every aspect of the production process, and such competence and methods used, considered issues of comprehensive strategy of organization and its operations.

In this direction and according to (Zack), technical ignorance is responsibility that is not carried by operations mangers only but are accepted by all managers. It does not have to be an engineer to become director of operations but basic knowledge of techniques are important and necessary and most importantly it is to learn how to raise questions about technology and its tools and understand how techniques fit with organizational strategy (Zack, 1999, P. 125). Some US companies missed global competitiveness in the seventies of the previous century and being blamed partly to technology haters.

The emergence and use of information and communication technology tools in recording and saving and circulating of information have a high impact on knowledge operations management that enables them to harness data information for planning and organizing which is tentative addresses not knowledge. This is the nature of the relationship between organizational and technological axes dimensions. Relationship information arises also in the opposite direction as individuals; groups and senior management are who controls the knowledge. Technology cannot play its role in operational objectives unless individuals are prepared to accept these tools and adapt to new working conditions (Jawad, 1996, P. 286), and the technological systems to better designed and better fixed are useless if rejected by individuals implicitly or explicitly.

There are several benefits proposed by (Swan) to possess expertise in information technology. The first benefit is 
that renewal products and production processes become more influential when runs both together, knowing the technological information production and production processes that enable us to understand the impact of the changes in one over the other. The second benefit is that acquisitions are powerful weapons against competitors. The third benefit, states that the organization is in a better position to maintain its operational and adjusted situation when necessary and when it follow up the design and operation of equipments (Swan, 1999, P. 1).

(Dattamajumar) distinguished the dynamic nature of knowledge applications and tools nowadays computerized via internet as essential tools in information creation (Dattamajumar, 2006, P. 367). Although the potential benefits of knowledge of the Internet are limited due to the limited expression through knowledge, computers are considered tools within the framework of the information processes. Lewis agrees with this view and confirms that techniques help us communicate over the Internet with the world using some simple commands, in the area of operations management several techniques used to dissemination and distribution of information to take any decisions and requires us to contain all available information including rigid knowledge into being so difficult to address such knowledge of computing, and rigid knowledge (Viscous Knowledge) equips with rich and quality data but mysterious and slow-motion once, but dynamic over time happens to turn this rigid knowledge to useful flexible once. Publishable knowledge is the knowledge that is generated from data and labor market information such as demand for the products, consumers ' tastes and required quality.

\section{Fifth dimension: operational knowledge management standards (how)}

Based on the previous investigation and research methodology and problem, as well as the opinions presented on knowledge management and operational standards adopted an option or advisory paths believes to create success strategy and processes to stay in business. Taking into account the relative importance of organizational knowledge dimensions and informational technological tools in this direction, and this explains the existence of an interactive process led by operational knowledge management between these cognitive dimensions and their variants and tools mentioned. So we find in formulating and defining the scope and nature of these dimensions and tools core content of the required management activity, and that is what we found compatible with what (Hendriks) suggested to study knowledge management perceptive and application when engineering and organizational portal were discussed and published in (2001) (Hendriks, 2001, P. 61) as well as (Roman's) philosophy advocated the operational and organizational learning portal provides access to the (Deming) who reached to the applied principles and how they can move into practice in the field of improving knowledge and competitiveness (Roman, 2001, P. 311).

The above opinions revealed that the pervasiveness of the operational knowledge management standard vision which is considered as the security valve for knowledge management, because it cannot be done in isolation from the operational knowledge organizational dimensions and technology tools and close relationship between them This was referred to as appropriate, based on human resources management measurement, organizational, structural, and technological information means to measure the ability to achieve link under strategic understanding for organization and operations. Organization's needs of individual's knowledge force base and what they believe and what they see of ideas or thought, as well as the role of the group or knowledge work teams (production of knowledge/organization, effort between individual and group).

Organizations should focus on wages, incentives, hierarchy, evolution and rewards knowledge within the organization in order to protect its stability and getting its human resources needed skill. The regulating instruments (knowledge establishing centers, operational communications, knowledge brokers, knowledge teams) trends are established by knowledge power protected within the organization. Therefore, emphasis on those efforts that provide convenient operational knowledge management design based on its four basic insights:

Organizational relationship with knowledge

Convenience classifications with knowledge

Knowledge perspectives with meaningful organizational vision

Dynamic properties and features of knowledge

Finally, vision popped which requires informational knowledge management co-existence between people, organizational structure and information technology (placed two axes), first, human knowledge and organizational knowledge. Second, it includes knowledge technological tools, in addition to the need to build a bridge between the two axes that expresses the concept of knowledge management relationship - a-in achieving the organization's strategy and operations because if we don't consider that it will reach half way without crossing.

\section{Sixth: Conclusions and recommendations}

This modest search is a bid by researcher to raise relevant model "informational knowledge management" toward organizational dimensions pivotal markup operational knowledge and information and communication technology tools that were subjected to systematic process of scientific method adopted in applicable theoretical research across relationship and evaluation of the strategic concept of operations management. During the relationship status, the study axes were determined and the operational knowledge management measures were determined and diagnosed to understand business organizations strategic concept for organization and its operations in the 
business world.

Based on the diagnosis and analysis of the relationship, the present researcher's efforts, including the study findings and recommendations, supported results groundwork through model designer. The following part will display all conclusions and recommendations consistent with the curriculum, the search method and its model. These conclusions summary focused as follows:

1) An increasing emphasis on the need to improve knowledge, because now it evolved into a competitive weapon and is no longer a technical process but one of the strategic goals of operations management. Therefore knowledge is a real opportunity that must get higher management attention and support and is considered one of the criterias for strategic performance that anticipates more attention in the coming time and by technological developments.

2) The study methodology for "operational knowledge management" content under contemporary concerns centered on two-way. The first is addressed under the concept of organizational knowledge dimensions. The second axis is the concept of technological tools and applying information philosophy. Based on this perception and the knowledge and organizational strategy and operations, this study begins the critical line in preparing for the evaluation of the relationship between organizational dimensions and information technological dimensions tools in operational knowledge management within the continued organization and operations strategy approach.

3) In literature, however, many specialists in the field of operations management and production are still unaware of its existence. In the case of organizations in which concepts of knowledge management dimensions were not clear. In other words, there is a need to link these dimensions with information technology tools and communications or there is a missing link between the two axes that can be achieved through complement of operational knowledge management to achieve the relationship between the two axes, important principle in the work and objectives and strategic plans needed to improve competitiveness.

4) Determining knowledge organizational dimensions are considered one of the major responsibilities of the senior management and the nature of events and activities and objectives of the organization's strategic process and thus its operations and its decisions. This means that the philosophy of this is an interactive process administered by operational knowledge management between organizational knowledge and technological information tools.

5) To facilitate the task of implementing what had been discussed, the study alerted on the need to focus on the five dimensions of a suitable framework to reflect the pioneer perceptions of the field of operational knowledge management without justifying the limitation under the pretext of scarcity forms or dimensions, but we found out that what we have proposed appropriate point and in depth to its needs and realize relationship.

6) The study adopted by the researcher in diagnosing the problem led to diagnose the questions raised and confirmed what the study indicated. The study showed a compulsory attention should be paid to operational knowledge management axes individually, note that the relationship between the two axes may contribute in improving organizational strategy and operations.

7) In light of the research methodology utilized and in particular to the relationship subject and through the credibility of the study model that verified the problem and learned how to monitor the impact of each of the two axes set for the proposed dimensions and their relationship. Therefore, this study contributed in providing a knowledge framework to support the decision makers in organizations to select the knowledge benefits of building an efficient management of operations.

8) The study revealed that organizational dimensions may improve the effectiveness of knowledge management also. Knowledge tools and communication technology have improved the effectiveness of knowledge management, but the relationship between the two themes reinforces the capacity of the organization's competitiveness that differs from previous cases that combined interrelated dimensions variables logically, rationally and operationally which enhances the competitiveness strength.

An update to the imperatives of study, recommendations are as follows:

1) The importance of adopting an "operational knowledge management module" what the study explained in planned situation where assessment applied to knowledge and its management in light of the five organizational dimensions.

2) In order to achieve accurate indicators and common goals for future studies especially in administrative sciences and production and operations management, the researcher recommends using this research methodology and model for being achieved:

A. This model answers a lot of questions that rose in administrative sciences search.

B. The study provides a proposal for the dimensions based on theoretical frameworks views and reflection contents writers to address operational knowledge management axes and organizations are to be clearer in order to absorb these dimensions affecting the possibility of improving organizations strategies design. 
1) Try to harness operational knowledge management standards (human resources management, organizational, and structural) through real opportunities expression in their vision, knowledge and expressions of the competitive situation of the organization in the site that is in line with their vision for the future.

2) The study recommends that this scientific method may be used by organizations and continue the hard work and analysis of its dimensions and the necessary elements and attendant of positive and negative effects on competitiveness for organizations stability and growth opportunities.

3) In studies framework, this study suggests expanding the field of the study in accordance with this model that represents a preliminary attempt to knowledge areas and its management within the field of operations management in general and knowledge management in particular, This entails the need for continuity of the dimensions of this study or add other dimensions and may be preferable to use the model adopted in the study.

\section{References}

Al-Khafaji, Nima A. (2004). Strategic Management, Portal, Concepts and Operations, Dar Althakafa and Publication. Amman, Jordan.

Boist, Max H. (1995). Information Space a Framework for Learning in Organization. press Ltd .

Camillus, N, and Venkatraman, John. (2007). C. Exploring the Concept of "Fit" in Strategic Management. Academy of Management, No.3.

Dattamajumdar. Captain, B. K. (2006). Creating Quality Consciousness. Productivity, Vol. xxvll., No.4. Jan.

Hendricks, Paul H. J. (2001). ICT to Knowledge Management System. Journal of Technology, (16).

Jawad, Shawki N. (1996). Business Administration and a Quantitative Perspective. Baghdad.

Jibreen, Hade A. (2003). Knowledge Operations Management. Third International Annual Scientific Conference, 28-30 July. Al- Zaytoonah University. Amman - Jordan.

Katzenback, Joh R. (1993). The Discipline of Teams. Harvard Business Review, (March-April) .

King, Pavid R. (1997). The Management of Engineering Production. London Printer Publishes.

Lee, Tom, Perry. (1993). Real-Time Strategy. N.Y. John Wiley and Sons, Inc.

Mills, Charles A. (2007). The Quality Audit / A Management Evaluation Tool. N.Y McGraw- Hill Publishing Company.

Packendroff, Johann. (1995). Inquiring In to Temporary Organization. New Directions for Project Management Research.

Roman, D. D. (2001). Managing Project a Systems Approach. Flsevier Science.

Stacey, Sven., and Erik. (1997). The Two Faces of Management International. Thomson Business Press, London.

Swan, J., and Scarbrough, H. (1999). Knowledge Management- The Next Target People In European. Conference On Information System, Jun, 23-25.

Teece, D. (2000). Research Directions for Knowledge Management. California Management Review.

Thomad H, Davenport. (1999). Process Innovation. Cambridge Harvard University. Press.

Vijay, Sath. (2005). Culture and Related Corporate Realities. Homewood Richard D. Irwin.

Zack, M. H. (1999). Developing Knowledge Strategy. California Management Review, 4.

Table 1. Knowledge Dimensions

\begin{tabular}{|l|l|}
\hline First Dimension & The relationship between knowledge and overall organizational strategy and operations. \\
\hline $\begin{array}{l}\text { Second } \\
\text { Dimension }\end{array}$ & $\begin{array}{l}\text { Relationship between knowledge and manifestations/classifications relative differences } \\
\text { defined results. }\end{array}$ \\
\hline Third Dimension & $\begin{array}{l}\text { The relationship between knowledge and organizational vision: } \\
\text { 1) The relationship between knowledge and organizational performance. } \\
\text { 2) The relationship between knowledge and individuals or groups work. }\end{array}$ \\
\hline $\begin{array}{l}\text { Fourth } \\
\text { Dimension }\end{array}$ & $\begin{array}{l}\text { The relationship between knowledge and dynamic properties: flows and knowledge } \\
\text { treatments. }\end{array}$ \\
\hline $\begin{array}{l}\text { Fifth } \\
\text { Dimension }\end{array}$ & $\begin{array}{l}\text { The relationship between the other dimensions and measures of knowledge management: } \\
\text { Human recourses management, organizing, and structural hierarchy. }\end{array}$ \\
\hline
\end{tabular}




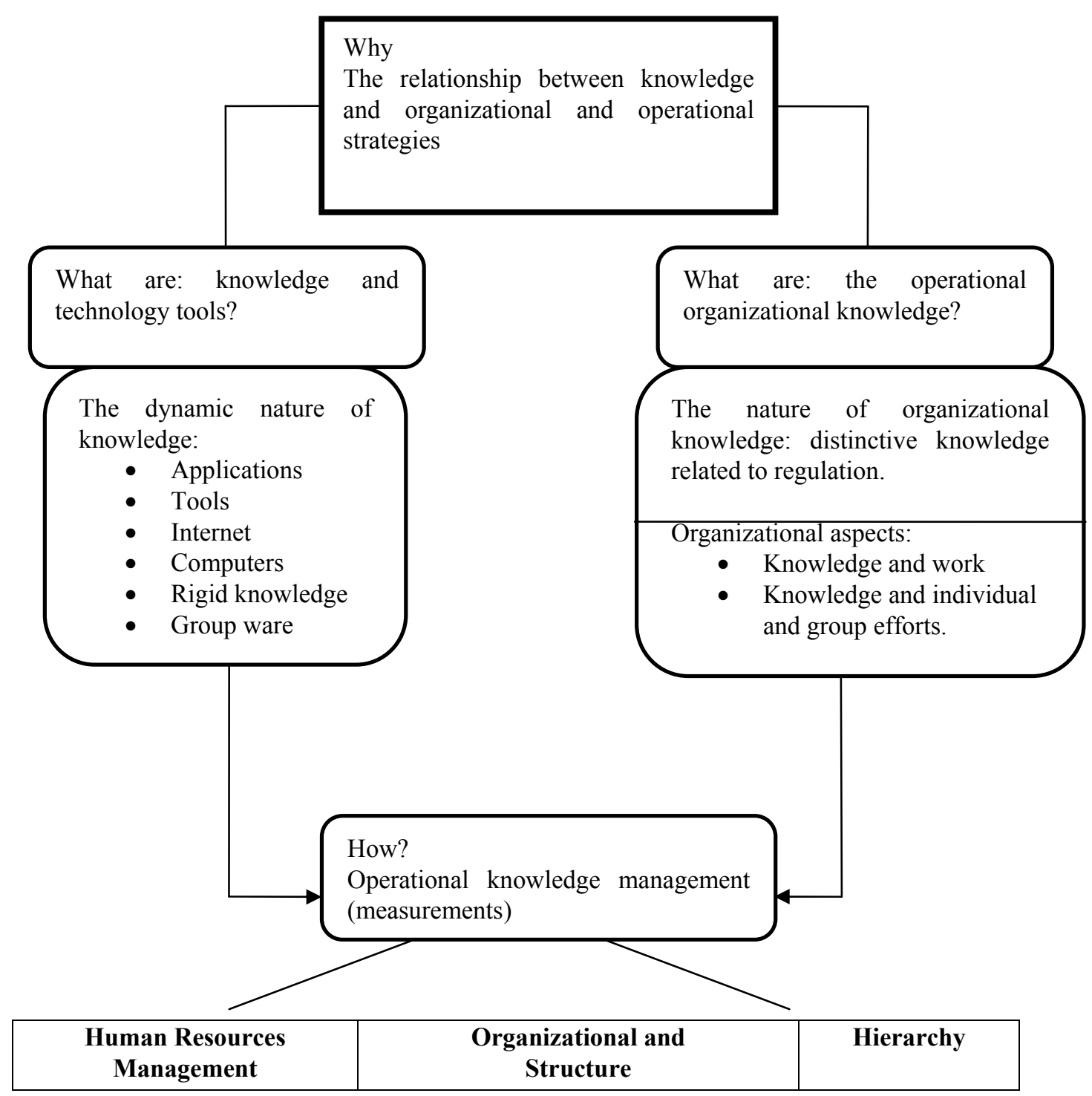

Figure 1. Research Model 